\title{
Níveis séricos de vitamina "A" em operários de Manaus, Amazonas
}

\author{
Helyde Albuquerque Marinho, (*) Thelma Suely França, (") Yolanda Silva Rebelo (*) \\ e Roger Shrimpton (")
}

\begin{abstract}
Resumo
O estado nutricional relacionado à vitamina " $A$ " foi estudado em 382 operários de ambos os sexos, de classe sócio-econômica baixa em quatro fábricas de Manaus, através da utilizaçāo dos niveis de Retinol e caroteno séricos e inquérito alimentar nas últimas 24 horas. Pôde-se constatar que os niveis séricos "abaixo de aceitáveis" de retinol em operários de três fábricas foi acima de $15 \%$ e o caroteno nos operários das quatro fábricas foi de $51,1 \%$. Os niveis séricos não mostraram diferenças significativas por faixa de renda, mas - consumo de vitamina " $\mathrm{A}$ " equivalentes em operários com niveis séricos de retinol alto eram significativa. mente mais altos do que os com niveis séricos de retinol baixo. A adequação de consumo de vitamina " $A$ " nas duas fábricas que ofereciam alimentação foi superior às necessidades recomendadas, enquanto as outras duas apresentaram um déficit de consumo de, aproximadamente, $45 \%$.
\end{abstract}

\section{INTRODUÇÃO}

A hipovitaminose A é problema de alta significação em Saúde Pública e freqüente em vários países em vias de desenvolvimento da América Latina, Asia Oriental e Meridional e. também, em algumas partes da Africa e Oriente Médio (Oomem, 1964; Patwartdham, 1979).

Papel vital desempenha a vitamina $A$ no crescimento, reprodução e resistência a doenças infecciosas e parasitárias no homem e animais (OMS, 1976). A hipovitaminose A pode ser conceituada como concentraçōes sangüineas de vitamina A deficientes acompanhadas de depleção tecidual geralmente resultante de baixo consumo alimentar prolongado ocasionando lesões clínicas.

No Brasil, a deficiência de vitamina A parece ser um dos mais importantes problemas de nutrição clínica, tendo vários trabalhos mostrados em diversas regiōes brasileiras, especialmente no Nordeste, ser problema de Saúde Pública (ICNND, 1965; Roncada, 1975 e Roncada et al., 1978) .
Vários estudos clínicos e inquéritos alimentares realizados na Amazônia têm mostrado a ingestão de vitamina $A$ baixa e sinais clínicos de hipovitaminose A (Silva, 1959; Giugliano et al., 1978a). Shrimpton \& Giugliano (1979) mostraram que a vitamina $A$ era um dos mais deficientes nutrientes nas dietas familiares de Manaus .

Não existem na literatura trabalhos sobre a concentração de níveis séricos de vitamina A na populaçăo Amazônica.

Com a esperança de esclarecer a importância de hipovitaminose A na Amazônia pro. pomos estudar niveis séricos de vitamina $A$ numa população de baixa renda de Manaus.

\section{MATERIAL E MÉTODOS}

Foram estudados 382 operários de ambos os sexos com idade compreendida entre 15 a 69 anos, de quatro fábricas de Manaus. Os operários foram escolhidos ao acaso nas fábricas, sendo que os salários percebidos eram abaixo de dois salários mínimos.

Duas fábricas foram recém-instaladas, localizadas no Distrito Industrial de Manaus. Classificamos como fábrica I e fábrica II. Os operários dessas fábricas recebiam assistência médico-alimentar. As outras duas fábricas. classificadas como III e IV, fundadas há bastante tempo, localizadas em bairros periféricos da cidade de Manaus, năo proporcionavam as assistências que as fábricas anteriores prestavam aos seus funcionários.

Cada operário foi inquerido em uma entrevista sobre a renda familiar e consumo alimentar nas últimas 24 horas. Os operários foram classificados segundo a renda familiar per capita em três classes; baixa, média e alta.

Os alimentos consumidos foram transformados em equivalente de retinol baseado na tabela de composição de alimentos da América

(•) - Instituto Nacional de Pesquisas da Amazônia, Manaus. 
TABELA 1 - Teores de caroteno sérico, segundo idade e sexo, em operários de quatro fábricas de Manaus. AM., 1979

\begin{tabular}{|c|c|c|c|c|c|c|c|c|c|}
\hline \multirow{3}{*}{$\begin{array}{l}\text { Idade } \\
\text { (anos) }\end{array}$} & \multicolumn{6}{|c|}{ SEXO } & \multirow{2}{*}{\multicolumn{3}{|c|}{ Total }} \\
\hline & \multicolumn{3}{|c|}{ Feminino } & \multicolumn{3}{|c|}{ Masculino } & & & \\
\hline & $n$ & $\bar{x}$ & s & $\mathrm{n}$ & $\bar{x}$ & s & n & $\bar{x}$ & s \\
\hline $10-19$ & 20 & 51,0 & 43,3 & 13 & 30,3 & 26,7 & 33 & 40,6 & 35,0 \\
\hline $20-29$ & 79 & 53.3 & 40,0 & 35 & 39,2 & 33,2 & 114 & 46,2 & 36.6 \\
\hline $30-39$ & 48 & 44.3 & 30,0 & 15 & 41,3 & 38,9 & 63 & 42,8 & 34,4 \\
\hline $40-49$ & 23 & 42,3 & 26,0 & 9 & 32,9 & 15.4 & 32 & 37,6 & 20.7 \\
\hline 50 & 10 & 48,8 & 33,8 & 21 & 35,0 & 29,7 & 31 & 41,9 & 31,7 \\
\hline TOTAL & 180 & 47,9 & 34,6 & 93 & 35,7 & 28,7 & 273 & 41,8 & 31,6 \\
\hline
\end{tabular}

Latina (Leung \& Flores, 1961). Utilizamos uma calculadora programável (Sharp PC 2000), segundo o método descrito por Johnson \& Nitzke (1974). Os dados estão sendo apresentados em outro trabalho com mais detalhes.

O sangue das trabalhadores foi coletado nas fábricas por via intravenosa e a separação do soro foi realizada logo em seguida no laboratório, permanecendo os mesmos congelados $\left(-20^{\circ} \mathrm{C}\right)$ por um periodo não superior a dois meses até serem usados para dosagem. O método adotado nas dosagens de retinol e caroteno sérico foi o de Bessey \& Lowry (1946), modificado (Araújo \& Flores, 1978). Os resultados foram classificados segundo recomendaçōes do ICNND (1963), adotado pela OPAS (1970).

Para verificar os efeitos da renda e consumo, as médias e desvios padrões foram calculados e a significação da diferença entre médias foi verificada pelo teste $T$ (Armitage, 1971).

\section{RESULTADOS, DISCUSSÃO E CONCLUSÃO}

Observa-se, na figura 1 , que os níveis séricos de vitamina " $\mathrm{A}$ " de $60 \%$ dos operários estão localizados como "aceitável". Constatou-se ainda o estado deficitário de vitamina "A", ou seja, teores menores que $10 \mu \mathrm{g} / 100 \mathrm{ml}$ no soro dos operários de duas fábricas (Fig. 1) . Geralmente, este estado tem tendência a associar-se com uma escassez da reserva hepática de vitamina " $A$ " e com um aumento na pre- valência de sinais clínicos de carência (OMS, 1976). Convêm esclarecer que não foi realizado o inquérito de sinais clínicos de deficiência de vitamina " $A$ " nesse trabalho, porém é sabido que as alterações bioquímicas da vitamina " $A$ " no sangue precedem as modificaçōes clínicas (OMS, 1978).

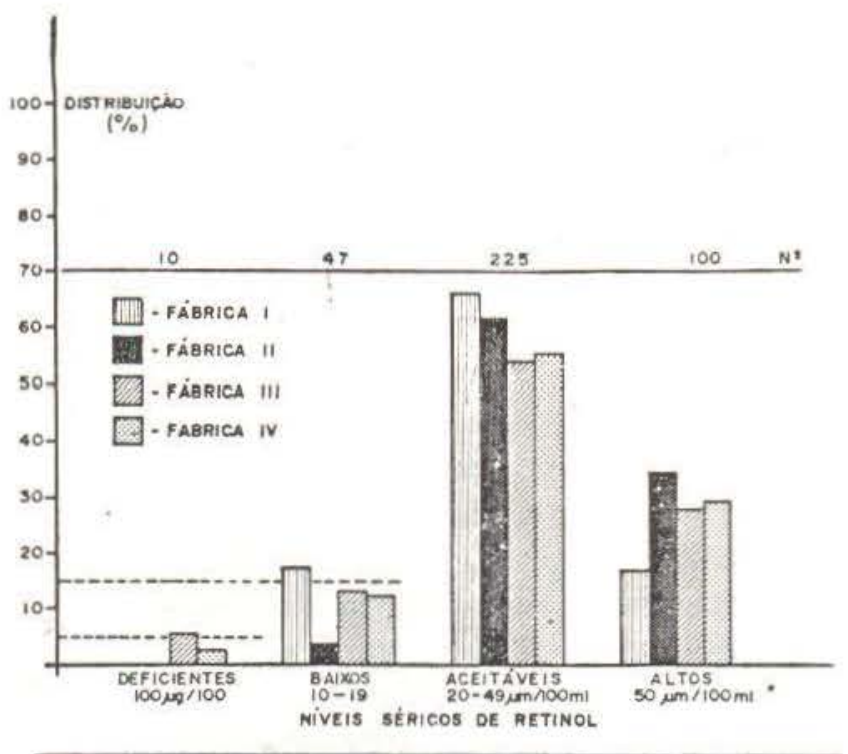

Fig. 1 - Distribuição percentual dos niveis séricos de vitamina $A$ em operários de ambos os sexos de Manaus-AM, 1979.

A fonte principal de vitamina " $A$ ", na maio. ria das dietas, é o Beta-caroteno. As concentrações séricas de caroteno são bastantes valiosas pois informam a ingestão recente dos mesmos. Os niveis desse nutriente no soro dos operários na classificação "deficiente" fo- 
TABELA 2 - Niveis de vitamina "A", segundo renda per capita e sexo, em operários de Manaus-AM., 1979

\begin{tabular}{|c|c|c|c|c|c|c|c|c|c|}
\hline \multirow{3}{*}{$\begin{array}{c}\text { Renda } \\
\text { Per Capita }\end{array}$} & \multicolumn{6}{|c|}{ SEXO } & \multirow{2}{*}{\multicolumn{3}{|c|}{ Total }} \\
\hline & \multicolumn{3}{|c|}{ Feminino } & \multicolumn{3}{|c|}{ Masculino } & & & \\
\hline & $\mathrm{n}$ & $\bar{x}$ & s & $\mathrm{n}$ & $\bar{x}$ & s & n & $\bar{x}$ & s \\
\hline BAIXA & 46 & 41,7 & 13,3 & 27 & 38,4 & 18.6 & 73 & 40,0 & 15.9 \\
\hline MEDIA & 79 & 41,9 & 15.1 & 39 & 41,0 & 16.1 & 118 & 41,4 & 15.3 \\
\hline ALTA & 78 & 42,5 & 15,9 & 47 & 42,1 & 14,4 & 125 & 42,2 & 15.1 \\
\hline TOTAL & 221 & 42,0 & 14,8 & 113 & 40,5 & 16,4 & 334 & 31,2 & 15,6 \\
\hline
\end{tabular}

ram elevados, aproximadamente $28 \%$ (Fig. 2) . Esses resultados estão em concordância com o inquérito alimentar, em que foi constatado baixo consumo de frutas e hortaliças (fonte de pro-vitamina "A") pelos operários das fábricas pesçuisacias .

Os resultados da tabela 3 e figura 3 mostram que os homens apresentaram concentraçōes baixas de caroteno sérico, em todas as faixas etárias, com exceção de uma, que também está no limiar da classificação "baixa", enquanto as mulheres apresentaram niveis normais confirmando as observações de Roels (1958). Gravesen (1967) e Roncada (1972) que encontraram níveis séricos de caroteno nos varões adultos mais baixos que nas mu. Iheres; estas possuiam retinol sérico mais bai-

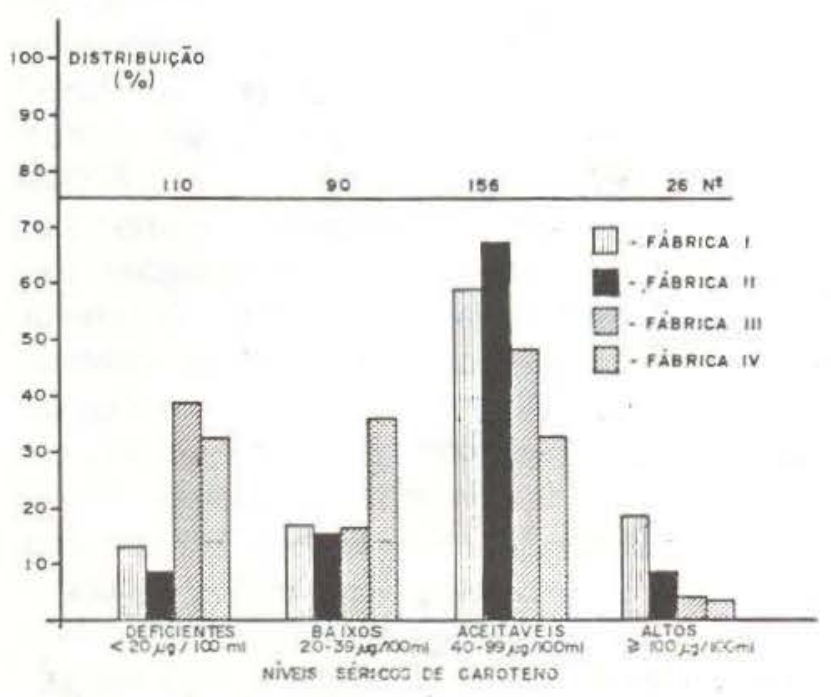

Fig. 2 - Distribuiçāo percentual dos níveis séricos de caroteno em operários de ambos os sexos de Manaus. AM, 1979 , xos do que os homens. Entretanto, essa segunda observaçăo não foi significativa estatisticamente (Fig. 3 e Tab. 3) .

A hipovitaminose " $A$ " apresenta-se especialmente entre os grupos de população de estado sócio-econômico baixo, usualmente alimentos com dietas deticientes. Procurou-se avaliar a situação da vitamina " $A$ ", também, por meio do estudo da renda familiar per capita, consumo de alimentos e vitamina " $A$ " sérica (Tab. 2 e 4 e Fig. 4). Não houve diferença significativa entre renda per capita, niveis séricos de retinol e sexo (Tab. 2).

Analisando-se a freqüência do consumo de alimentos é de estranhar-se a baixa freqüência de consumo de certos frutos tropicais como buriti, pupunha, umari, abricó, tucumă, e outros considerados, como fontes excepcionais de vitamina "A" (Guimarães \& Pechnick, 1956 e Agguiar et al., 1981). A farinha de mandioca amarela, um dos alimentos básicos e comuns

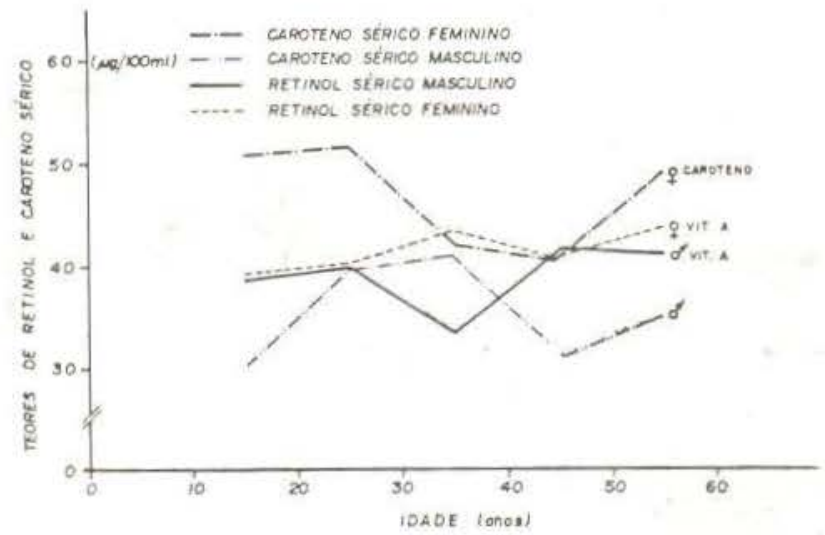

Fig. 3 - Teores de retinol e caroteno séricos segundo idade e sexo em operários de Manaus-AM, 1979. 
TABELA 3 - Niveis de vitamina "A" sérica $(\mu \mathrm{g} / 100 \mathrm{ml})$, segundo idade e sexo, em operários de Manaus-AM., 1979

\begin{tabular}{|c|c|c|c|c|c|c|c|c|c|}
\hline \multirow{3}{*}{$\begin{array}{l}\text { Idade } \\
\text { (anos) }\end{array}$} & \multicolumn{6}{|c|}{$S E X O$} & \multirow{2}{*}{\multicolumn{3}{|c|}{ Total }} \\
\hline & \multicolumn{3}{|c|}{ Feminino } & \multicolumn{3}{|c|}{ Masculino } & & & \\
\hline & $\mathrm{n}$ & $\bar{x}$ & s & $n$ & $\bar{x}$ & s & $\mathrm{n}$ & $\bar{x}$ & $\mathrm{~s}$ \\
\hline $10-19$ & 25 & 38,3 & 13,0 & 19 & 39,2 & 17,2 & 44 & 38,7 & 15,1 \\
\hline $20-29$ & 93 & 40,1 & 14,7 & 42 & 39,3 & 14.6 & 135 & 39.7 & 14,6 \\
\hline $30-39$ & 53 & 46,0 & 13,4 & 16 & 37.4 & 16,8 & 69 & 41,7 & 15,1 \\
\hline $40-49$ & 26 & 41,7 & 18,0 & 14 & 42,4 & 21.5 & 40 & 41,3 & 19,7 \\
\hline 50 & 9 & 47,0 & 16,2 & 25 & 42,0 & 12,9 & 34 & 44 & 14,5 \\
\hline TOTAL & 206 & 42,7 & 15,0 & 116 & 39,8 & 16,6 & 322 & 41,1 & 15,8 \\
\hline
\end{tabular}

na região amazônica, contém carotenóides precursores de vitamina "A" (Maravalhas, 1964; Marinho \& Arckoll, 1980). A tabela de composic̣ão de alimentos usada neste trabalho não menciona a presença de pro-vitamina "A" na farinha. O desconhecimento da cor da farinha consumida (branca ou amarela) no momento do inquérito alimentar contribuíram para a omissão da farinha de mandioca como uma das possiveis fontes de vitamina " $A$ ", visto ter sido o alimento de maior freqüência $(88,9 \%)$. Verificou-se ainda que as ingestōes diárias de vitamina " $A$ " dos operários da fábrica I e II estão acima das recomendações $(750 \mu \mathrm{g})$ da Food an Nutrition Board, 1974 (Tab. 4). Constatou-se, ainda, a ingestão de fígado de boi pelos trabalhadores da fábrica II, enquanto que as ingestas de vitamina " $A$ " pelos trabalhadores de outras duas fábricas foram insatisfató. rias (Tab. 4), ássemelhando-se com a ingestão encontrada nas populações da Venezuela e Colômbia (OPAS, 1970) e em Iguape, São Paulo (Roncada, 1972) .

TABELA 4 - Consumo médio de vitamina "A" em cada fábrica

\begin{tabular}{c|c|c}
\hline $\begin{array}{c}\text { Especificaçăo } \\
\text { Fábrica }\end{array}$ & N.॰ & $\bar{x}\left({ }^{*}\right)$ \\
\hline I & 52 & 1025,0 \\
II & 58 & 5573,1 \\
III & 99 & 395,8 \\
IV & 173 & 437,9 \\
Todas & 382 & 1857,9 \\
\hline (•) o/100g
\end{tabular}

Niveis sangüíneos de vitamina " $A$ " abaixo do normal acompanhados por baixos niveis de caroteno sugerem a existência de depósitos inadequados de vitamina " $A$ " (Pearson, 1962). As figuras 1 e 2 apresentam resultados que parecem confirmar depósitos inadequados de retinol. Os baixos niveis séricos de retinol dos traba!hadores estão associados com o deficit de consumo desse nutriente (Fig. 4) .

Operários das fábricas I e II tiveram ingestão de retinol alta (Tab. 4), no entanto, os niveis séricos de vitamina " $A$ " e caroteno dos trabalhadores da fábrica I estão abaixo de "aceitável" em 17,0\% para vitamina "A" e $30,2 \%$ para o caroteno (Fig. 5). Este fato pode estar associado a uma ingestão proteínica insuficiente, a uma parasitose ou, possivelmente, a uma deficiência de zinco (Harper, 1975; Leopold, 1978). Shrimpton \& Giugliano (1979) mostraram que a dieta em. Manaus não é deficiente em proteínas; muito pelo contrário, che gando a ser o dobro das recomendaçōes per capita por dia. Quanto aos parasitas intestinais, um levantamento dos trabalhos, publicados desde 1944 até 1977, revelou um indice de positividade não inferior a $80 \%$ nas zonas urbanas e rurais do Amazonas (Giugliano et al., 1978b). Raros são os trabalhos sobre zinco na região amazônica. Segundo Shrimpton (1980), o consumo familiar da cidade de Manaus relativo ao zinco é inferior a $70 \%$ das recomendações diárias americanas.

Borges (1978) usou doses orais maciças de vitamina "A" de (200.000 UI) em pré-escolares mostrando a ineficácia para elevar os ni- 


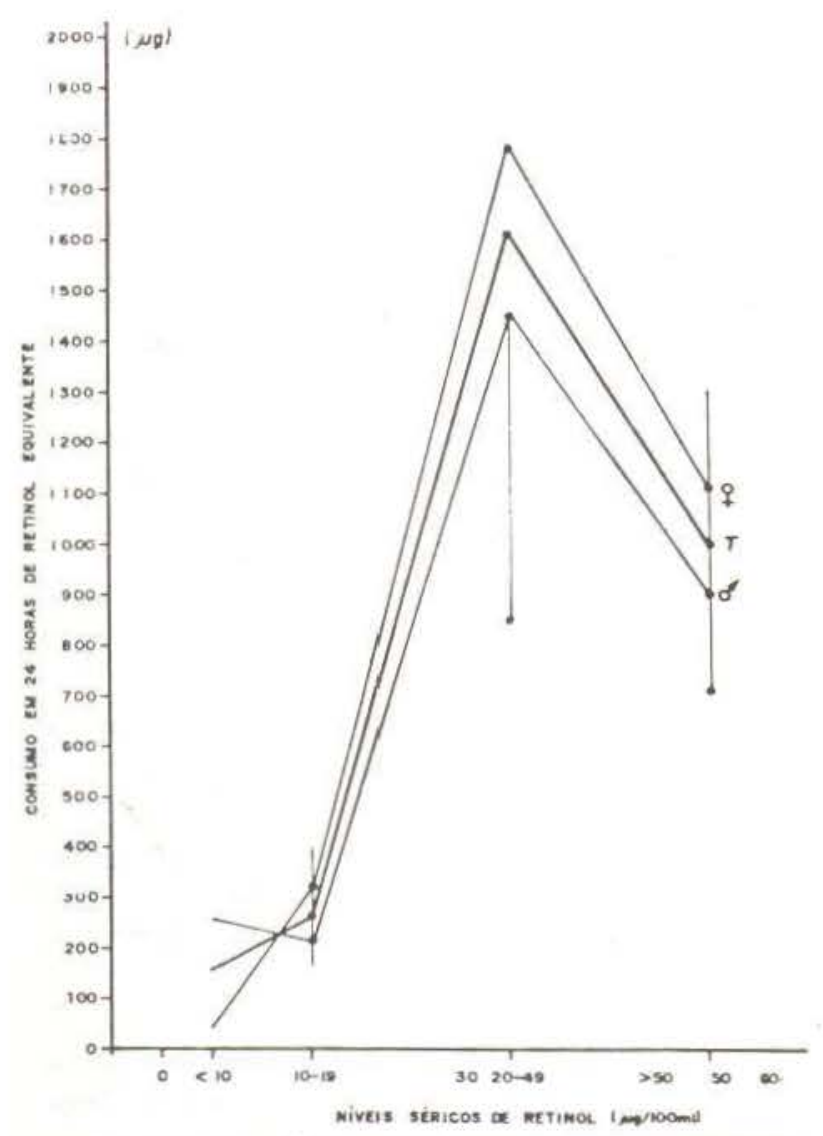

Fig. 4 - Consumo de vitamina $A$ segundo niveis séricos de vitamina A e sexa em operários de Manaus, 1979.

veis séricos de vitamina " $\mathrm{A}$ ". Por outro lado, 0 uso de açúcar fortificado com vitamina " $A$ " elevou estatísticamente os valores médios de retinol plasmático. Entretanto, o tratamento das parasitoses gastrintestinais nesses pré-escolares também resultou em aumento dos níveis séricos de retinol, mesmo sem a suplementação.

Deste modo, são remotas as possibilidades de a proteína estar associada à má absorção da vitamina " $A$ " na população do Amazonas. ficando dúvidas quanto à baixa ingestão de zinco e parasitoses intestinais endêmicas em nosso meio, fazendo-se necessários e urgentes estudos a esse respeito.

$\mathrm{O}$ inquérito alimentar e bioquímico referente à vitamina " $A$ " revela deficiência desse nutriente em adultos. Isso induz a crer que os grupos vulneráveis devam apresentar estado carências mais graves ainda.

Considerando o critério formulado pelo ICNND (1963) e adotado pela OPÁS (1970) sobre os níveis séricos de vitamina " $A$ ", os quais estabelecem condições de saúde pública, os resultados aqui encontrados permitem concluir que os trabalhadores das fábricas I, III e IV são populações de alto risco, pois possuem niveis séricos de retinol abaixo do aceitável, superior a $15 \%$ (Fig. 5).

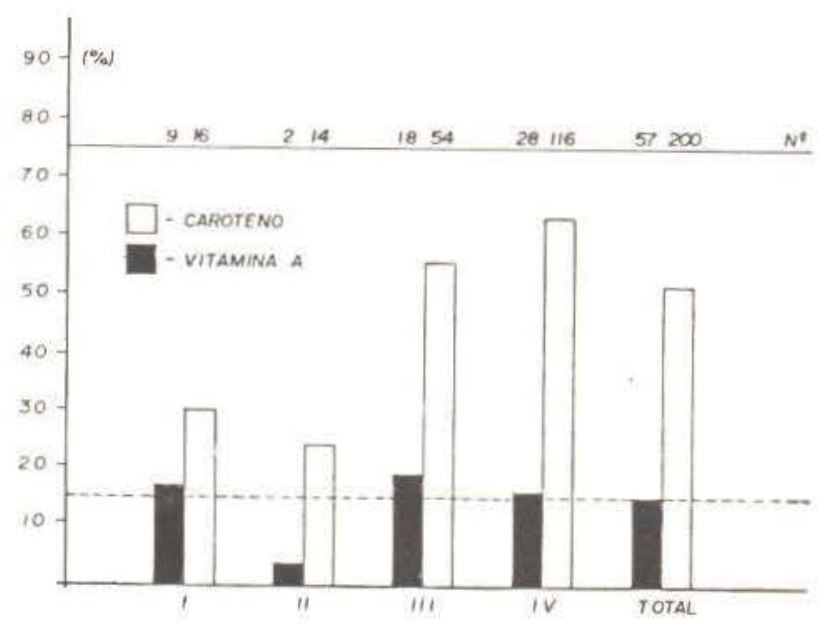

Fig. 5 - Distribuição percentual dos niveis séricos de vitamina A e caroteno abaixo de "aceitável" em operários de ambos os sexos em quatro fábricas de ManausAM, 1979.

Baseados nos nossos resultados, sugerimos: (1) o credenciamento das empresas ao programa de alimentação ao trabalhador; (2) elaboração de cardápios balanceados; (3) utilização dos alimentos locais, respeitando os hábitos alimentares; (4) um programa de educação alimentar seria altamente recomendável para melhoria de adequação de vitamina " $A$ " na dieta; (5) um estudo mais detalhado sobre os fatores que contribuem para a má absorção de vitamina " $A$ "; e (6) o enriquecimento do açúcar com vitamina " $A$ " para o uso pela população, visando a diminuir a prevalência de individuos com valores séricos de retinol deficientes.

\section{SUMMARY}

Serum vitamin " $A$ " and carotene levels were determined in 382 low income worker of four factories in Manaus, Amazonas, Brazil. The results were compared by sex and age, levei of vitamin " $A$ " intake the previous twenty four hours, and socio-economic status. In the factories more than $15 \%$ of worker had lower than acceptable serum vitamin " $A$ " levels. The vitamin " $A$ " intake in the two factories with meals provided was satisfactory but in the two factories with out fac- 
tory meals intake was $55 \%$ of the Recomended Dietary Allowance. Serum retinol levels were not significantly different for income groups, age or sex but vitamin " $A$ " intake was significantly higher for workers with high normal serum retinol levels than for those with low serum retinol levels.

\section{REFERENCIAS BIBLIOGRAFICAS}

AGUIAR, J.P.L.; MARINHO, H.A.; REBELO, Y.S.;

SHRIMPTON, R.

1980 - Aspectos nutritivos de alguns frutos da Amazônia. Acta Amazonica, 10 (4): 755-58.

ARAUJO, C.R.C. \& FLORES, H.

1978 - Improved Spectrophotometric Vitamin A Assay Clinical Chemistry. 24: 338 p.

ARMITAGE, P.

1971 - Statistical methods in medical research. Blackwell Scientific. Publ., Oxford. 804 p.

BESSEY, O.A. \& LOWRY, O.H.

1946 - The determination of vitamin $A$ and carotene in small quantites of blood serum. J. Biol. Chem., 166: 177 p.

BORGES, E.L.

1978 - Efeito do Consumo de Açúcar fortificado com vitamina A por pré-escolar - Tese de Mestrado em Ciências - U.F.M.G. 46 p.

FOOD AND NUTRITION BOARD

1974 - National Academy of sciences Nacional Rebearch Council.

GIUGLIANO, R.; ALBUOUEROUE, H.C.R.; SHRIMPTON, R.

1978a - Estudo Antropométrico, clinico e de padrões alimentares em um grupo de escolares de Manaus, 1976. Acta Amazonica, 8 (1): 7582 p.

GIUGLIANO, R.; SHRIMPTON, R.; ARKCOLL; GIUGLIANO. L.G.; PRETERE, M.

1978b- Diagnóstico da realidade alimentar e nutricional do Estado do Amazonas, 1978. Acta Amazonica, 8 (2): Suplem. 2.

GRAVESEN, K.J.

1967 - Vitamin A and carotene in serum from healthy danish subjects scand. J. Clin. Lab. Invest., 20: 57-62 p.

GUIMARÃES, L.R. \& PECHNIK, E.

1956 - Contribuição ao estudo dos alimentos da regiāo Amazônica. Arg. Bras. de Nutriçăo, 15: 1: $15-24 \mathrm{p}$.

HARPER, H.A.

1975 - Review of physiological chemistry. Los Altos, Lange Medical Publications, 15: $441 \mathrm{p}$.
INTERDEPARTMENT COMMITTE ON NUTRITION FOR NATIONAL DEFENSE

1963 - Nutrition survey.

1965 - Northeast Brazil, nutrition survey. Washington, D. C.

JOHNSON, N.E. \& NITZKE, S.

1974 - A reporting system for nutrient adequacy Home. Econ. Rev. J. 2: 210-221 p.

LEOPOLD, I.H.

1978 - Zinc Deficiency and visual Impairment? American Journal of Ophthalmology, 85: 6-871.

LEUNG, W.W. \& FLORES, M.

1961 - Food composition tables for use in Latin America. INCAP - ICNND. Maryland. 145 p.

MARAVALHAS, $\mathrm{N}$.

1964 - Cinco estudos sobre a farinha de mandioca. Publ. do INPA, Série Química, (6).

MARINHO, H.A. \& ARKCOLL, D.B.

1981 - Estudos sobre o caroteno em algumas variedades Amazônicas de mandioca (Manhihot esculenta Crantz). Acta Amazonica, 11 (1): 71.76 .

OOMEN, H.A.P.C.

1964 - A global survey on xerophtalmia and public health aspects of hypovitaminosis A. Trop. Geog. Med., 16: 271.315.

ORGANIZACION PANAMERICANA DE LA SALUD.

COMITE TECNICO ASESOR EN NUTRICION. (OPAS)

1970 - Hipovitaminosis A en las Americas. Washington. D.C. (Publ. cient., 198)

ORGANIZACION MUNDIAL. DE LA SALUD

1976 - Carência de vitamina A y Xeroftalmia. 11 p.

1978 - Guia prático para la deteccion, prevención y tratamento de la xeroftalmis. $9 \mathrm{p}$.

PATWARDHAN, V.N.

1969 - Hypovitaminosis A and epidemiology of xerophthalmia. Amer. J. Clin. Nutr., 22: 1166.

PEARSON, W.N.

1962 - Biochemical appraisal of nutritional status in man. Amer. J. Clin. Nutr., 11: 462-76 p.

ROELS, O.A.

1958 - Carotene balances on boys in Ruanda where vitamin A deficiency in prevalent. J. Nutr., 65: $115-27 \mathrm{p}$.

RONCADA, M.S.

1972 - Hipovitaminose "A", níveis séricos de vitamina " $A$ " e caroteno em populaçōes litorâneas do Estado de São Paulo, Brasil. Rev. de Saúde Pública, 6:1: $3 \mathrm{p}$.

1975 - Inquérito entre migrantes atendidos pela Central de Triagem e encaminhamento, na Capital do Estado de São Paulo, Brasil II Aspectos bioquímicos da hipovitaminose $A$. Rev. Saúde Pública, São Paulo, 9: 313 p. 
RONCADA, M.J.; WILSON, D.; NETTO, A.; NETTO, O.B.; KALIL, A.C.; NUNES, M.F.; OKAMI, E.T.

1978 - Hipovitaminose A em filhos de migrantes nacionais em trânsito pela Capital do Estado de São Paulo, Brasil. Estudo Clínico Bioquímico. Rev. Saúde Pública, São Paulo, 12: 3: $145 \mathrm{p}$.

SHRIMPTON, R.

1980 - Studies on Zinc nutrition in the Amazon Valley. Tese de Doutoramento Faculty of Medicine of the University of London.
SHRIMPTON, R. \& GIUGLIANO, R.

1979 - Consumo de Alimentos e alguns nutrientes em Manaus - 1973/1974. Acta Amazonica, 9 (1): $117-141 \mathrm{p}$.

SILVA, W.

1959 - Inquérito sobre o consumo de alimentos e nutrientes, avaliação do estado nutricional e situaçăo econômica da populaçăo Amazô. nica. Bol. Com. Nac. Alim., 4 (2): JulhoSetembro R.J.

(Aceito para publicaçẫo em 15/06/81) 